\title{
A Literatura Comparada como dobra crítica e a estrutura paranoica da racionalidade enciclopédica ${ }^{1}$
}

Henrique de Oliveira Lee

Doutorando em Literatura Comparada / UFMG; bolsista FAPEMIG

\begin{abstract}
RESUMO
No seminário "Le concept de littérature comparée et les problèmes théorique de la traduction”, lecionado em Yale em 1979-80, Jacques Derrida explora aspectos institucionais e disciplinares da "Literatura Comparada". Este trabalho tem por objetivo remontar e discutir argumentos da primeira sessão do seminário de 1979 e apontar a sua ligação com formulações posteriores, tal como a noção de Literatura como uma "instituição sem instituído".
\end{abstract}

Palavras-chave

Literatura Comparada, Jacques Derrida, Instituição

\section{INSTITUIÇÃO E TEXTO: LÓGICAS FARMACÔNICAS}

A primeira sessão do seminário de Derrida de $1979-80$ se abre a partir de questões relativas à institucionalidade da Literatura Comparada. Em sessões ulteriores do seminário será aludida a idéia de uma "crise” da Literatura Comparada. A discussão sobre a institucionalidade da Literatura Comparada está endereçada ao questionamento e redimensionamento dessa suposta “crise” disciplinar.

Derrida inicia a sua análise por aquilo que ele considera o problema mais basal de uma instituição, a sua legitimidade. "Existir, para uma instituição, é afirmar seu direito de existência, é se referir, em permanência mais ou menos virtual, a uma

\footnotetext{
${ }^{1}$ Este trabalho é parte do resultado de uma pesquisa realizada, com o apoio da CAPES, nos arquivos de Jacques Derrida e Wolfgang Iser alocados na University of California at Irvine.
} 
legitimidade, mas a um certo tipo de legitimidade particular, uma legitimidade histórica, um título que toma sua origem num ato de fundação histórica.”2

Portanto, é no ato de fundação histórica - que é um acontecimento e um drama de (auto) nomeação - que o texto institucional começa a ser escrito, lançando-se como uma promessa em direção ao futuro; mas, uma vez que o ato de fundação histórica toma lugar, a instituição se abre para vicissitudes. Uma delas é a contestação - interna ou externa - de seu ato de fundação por uma outra pretensão de legitimidade. Se um sujeito não tem mais a necessidade ou a possibilidade de referir-se ao ato fundacional de uma instituição, para legitimar o trabalho que cumpre em nome dessa instituição, poder-se-ia concluir que ela está morta.

No entanto, pensar a existência da instituição a partir de termos como “vida” e “morte” é um modo de explorar uma crença reassegurante:

Ter-se-ia a origem viva e autêntica de uma instituição, fonte viva de sua legitimidade e de sua finalidade intencional, seu desenho, seu programa, seu thelos, ou sua alma, e quando essa finalidade vivente cessa de animar a comunidade de sujeitos (aqui, pesquisadores, professores e estudantes), então que ela não permanece mais do que como uma fachada, corpo dissecado, uma reprodução estéril e mecânica. ${ }^{3}$

A oposição binária entre a "alma viva” e o “corpo morto” de uma instituição, entre a fonte de sua vida legítima e a reprodução mecânica de sua legalidade, é uma estratégia que serve de ensejo para que Derrida possa designar termos regidos por uma lógica farmacônica, que resistem à oposição entre vida e morte. São eles:

1. Instituição 2. Literatura 3. Tradução, e por consequência 4. Departamento de Literatura Comparada

Derrida comenta logo em seguida:

As três coisas que venho a nomear, instituição, literatura e tradução, eu deveria dizer antes mesmo, são as condições da língua, da língua escrita, da linguagem e/ou da escritura, enquanto palavras sob as quais abundam problemas, mas que deixo nesse instante em seu estado de senso comum - se alguma coisa como tal existe. Quem contestará que

${ }^{2}$ DERRIDA. Le concept de littérature comparée et les problèmes théorique de la traduction, sessão 1, p. 1. (Todas as citações referentes a esse seminário de Derrida foram traduções nossas.)

${ }^{3}$ DERRIDA. Le concept de littérature comparée et les problèmes théorique de la traduction, sessão 1, p. 2. 
sem língua, atos e eventos de linguagem, alguma instituição, alguma literatura, alguma tradução teria a mínima chance de aparecer ou mesmo de serem imaginadas? ${ }^{4}$

Uma língua é uma instituição simultaneamente consolidada e renovada por sua literatura; seus limites são transgredidos e estabelecidos pelas possibilidades da tradução, pela sua relação com outras línguas. Pensemos um dicionário, por exemplo, o dicionário é um texto/instituição, um "texto" que se apresenta como um conjunto no qual encontra-se registrado o tesouro da língua em um “estado” considerado como dado, e uma “instituição” a qual se recorre para arbitrar se determinados usos da linguagem pertencem ou não ao que se considera o tesouro da língua como sua expressão oficial. Para que o dicionário seja possível ele só pode existir como um corpus finito e definido de expressões linguísticas, portanto, como uma língua "morta”.

As possibilidades da Literatura e da Tradução se ligam à cristalização e à transgressão, simultâneas, da instituição “dicionário”, pois a Literatura e a Tradução colocam em questão e em movimento a capacidade da língua de produzir efeitos e acontecimentos, entreter a vida por repetições que são, ao mesmo tempo, vivas e mortas. Acontecimentos em uma língua - até para que possam ser percebidos enquanto tal - devem ser reinvestidos como traditio; ou seja, como tradução /tradição do sentido para além e independentemente da intencionalidade viva que o visa, que o contem, que o suporta.

O desenho que procura traçar as equivalências de língua e instituição com a noção de escritura toma contornos mais nítidos através da ênfase das lógicas farmacônicas pelas quais os vetores de vida e morte se imiscuem. Derrida chega a falar de uma "iterabilidade tradicionante da escritura”, razão pela qual

não se pode mais opor, tratando-se de instituição de literatura ou de tradução (e por exemplo, departamento de Literatura Comparada) a origem viva da instituição, que se relacionará com uma finalidade intencional estendendo sobre um mesmo objeto ideal uma comunidade de sujeitos viventes, e de outro lado uma repetição morta e moribunda, uma sobrevivência de fachada, uma comédia mecanizada. Estes dois termos não se deixam jamais opor ou mesmo dissociar em um texto (texto de instituição, texto literário texto de tradução), não mais que se

\footnotetext{
${ }^{4}$ DERRIDA. Le concept de littérature comparée et les problèmes théorique de la traduction, sessão 1, p. 3.
} 
deixariam separar um original vivente e autêntico de um lado, um duplo, uma cópia, um simulacro de outro. ${ }^{5}$

Dada as aproximações entre Texto e Instituição, Derrida partirá para uma análise breve, mas fundamental, em sua argumentação, das questões colocadas pela "tradução" dessa instituição, a Literatura Comparada.

\section{LITERATURA COMPARADA, LITERATURA COMPARATIVA: O LUGAR TRADUÇÃO}

Seguindo uma estratégia textual recorrente em seu trabalho, Derrida declara que gostaria de iniciar seus questionamentos do modo mais ingênuo possível a respeito da tradução da expressão “Literatura Comparada”.

"Literatura Comparada” e “Comparative Literature”: essas expressões são equivalentes, apesar das notórias diferenças da tradução. Certamente, são diferenças que se neutralizam na prática corrente, mas que podem ter uma importância significativa neste contexto. Contudo, ainda estamos falando apenas de uma diferença "tradutória” e deixando de lado diferenças de estilo e geográficas entre aquelas instituições designadas por essas duas expressões. Mas, nos diz Derrida,

esse ligeiro desvio de tradução, mesmo que neutralizado por práticas correntes, deve traduzir alguma coisa. Em todo caso, trata-se da tradução do conceito mesmo de literatura comparada, de disciplinas instituídas e práticas regradas no centro das quais a tradução e a pluralidade de línguas têm um papel organizador. ${ }^{6}$

Derrida afirma que esse desvio de tradução “deve traduzir alguma coisa”, e quando se faz equivaler termos que possuem uma diferença em torno do polo passividade/atividade, no sentido de comparada e comparativa, podemos começar a suspeitar de um caráter de generalidade estruturalmente necessário à formação da disciplina que se expressa na indecidibilidade do lugar da Literatura, que pode transitar do comparante ao comparado.

Outra suspeita levantada com relação ao sintagma “comparada/comparativa” é de ordem epistemológica. As palavras comparada, comparativa são singulares quando qualificam uma ciência, uma pesquisa, um objeto de estudo. No limite, pode-se dizer

\footnotetext{
${ }^{5}$ DERRIDA. Le concept de littérature comparée et les problèmes théorique de la traduction, sessão 1, p. 4

${ }^{6}$ DERRIDA. Le concept de littérature comparée et les problèmes théorique de la traduction, sessão 1, p. 5.
} 
que toda episteme é comparativa; ela possui uma unidade de objeto para que através dela se compare exemplos, casos, espécies, tipos. "Mas, então, por que existe uma disciplina chamada "Literatura Comparada?”7 A Antropologia, a Zoologia e a Química são comparativas, mas não adotam o predicativo “comparada” em suas denominações, pois é como se ele fosse sempre implícito.

Para prosseguir nesse questionamento da literalidade do título "Literatura Comparada”, Derrida nos sugere uma distinção massiva em caráter provisório, “ao menos cômoda o suficiente para começar", entre a literatura comparada a "ela mesma” e "Literatura Comparada”, que funcionaria no seguinte sentido: de um lado, a literatura ela mesma, idêntica a ela mesma, se compara a ela mesma, e no ato de comparação ela está como sujeito e objeto ao mesmo tempo, como comparante e comparado. De outro, o sentido da comparação com uma atividade não literária, uma atividade não literária compara a literatura. Nos dois casos, ao se começar a comparar

é preciso pressupor um saber essencial de essências gerais comparáveis (assim é preciso pressupor um saber quanto a essência do literário em geral, a existência de um elemento literário e idêntico a ele mesmo, elemento que se revela em toda literatura nas diferentes línguas nacionais e gêneros). ${ }^{8}$

No primeiro sentido da distinção, de algumas obras literárias, inicialmente a título de virtualidade e depois mais concretamente, é legítimo falar de uma Literatura Comparada. Toda vez que uma obra incorpora transformando, traduzindo, enxertando, elementos vindos de outras obras literárias, outros gêneros, outras esferas linguísticas e culturais, supondo-se que essas coisas tenham uma identidade rigorosamente definida, pode-se deduzir isso de uma Literatura Comparada, comparada a ela mesma.

No segundo sentido, a literatura é tomada como um objeto; trata-se de uma “instituição universitária” no modelo ocidental a que se chama "Literatura Comparada”, com um projeto teórico, pesquisas e atividades de caráter não literário. Uma instituição que possui uma história relativamente breve, uma geografia, um processo jurídico de legitimação.

Como já dito anteriormente, ambos os sentidos pelos quais a Literatura Comparada seja tomada apelam para uma essência geral tácita do que é a literatura,

\footnotetext{
${ }^{7}$ DERRIDA. Le concept de littérature comparée et les problèmes théorique de la traduction, sessão 1 , p. 8.

${ }^{8}$ DERRIDA. Le concept de littérature comparée et les problèmes théorique de la traduction, sessão 1, p. 9.
} 
essência através da qual se deduzirá a literatura apesar das diferenças das línguas nacionais. O horizonte de uma "literaridade" geral que permita selecionar, classificar, intitular fenômenos literários e comparar fenômenos comparáveis. Mas essa generalidade essencial que forma o a priori comparatista não é deduzida dos próprios trabalhos comparatistas. Pois, na ausência desta pré-compreensão do que é o literário, corre-se o risco de se comparar qualquer coisa com qualquer coisa em nome da Literatura Comparada. Pode-se comparar, e é Derrida quem fornece os exemplos, "uma pintura e uma planta real, um livro de culinário e um texto constitucional, um romance e um cheque bancário, o discurso do presidente Carter com a Ilíada”. ${ }^{9}$

Por mais absurdos que esses exemplos possam parecer, sabemos que na falta de um a priori rigoroso, de uma essência rigorosamente protegida por sua a prioridade, pode-se sempre justificar o pertencimento de tais comparações ao campo da Literatura Comparada. E como a existência de uma literaridade pura permanece ainda hoje - mais do que nunca - problemática, a Literatura Comparada pode, ao ver de Derrida, se transformar tanto em uma disciplina "errante, delirante e bulímica”, ${ }^{10}$ quanto em uma disciplina de um enciclopedismo desenfreado: nada do que é da linguagem me é estrangeiro, nada do que é arte me é estrangeiro.

No caso de a Literatura Comparada caminhar na direção do enciclopedismo desenfreado, Derrida, vislumbra o seguinte desdobramento:

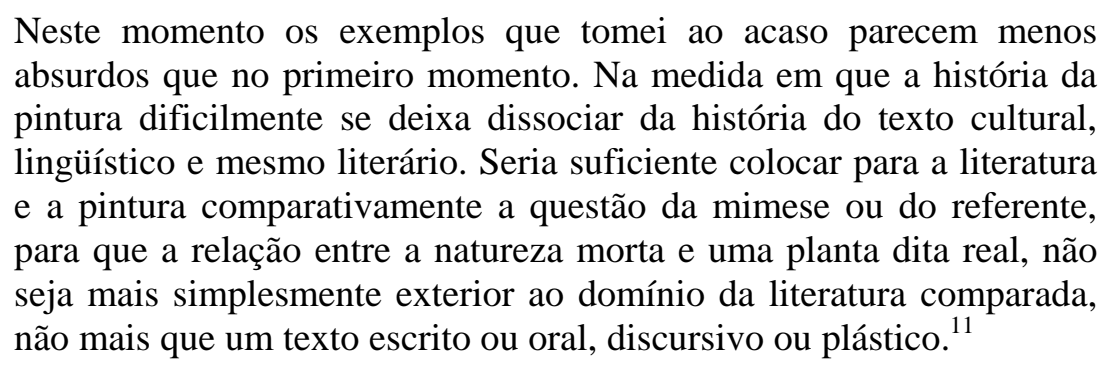

Com esse argumento Derrida destaca aquilo que ele chama da "tentação estrutural” à abertura enciclopédica, asseverando que é preciso compreendê-la para que se deduza daí também os limites daquilo que se pretende como o campo da Literatura

\footnotetext{
${ }^{9}$ DERRIDA. Le concept de littérature comparée et les problèmes théorique de la traduction, sessão 1, p. 10.

${ }^{10}$ DERRIDA Le concept de littérature comparée et les problèmes théorique de la traduction, sessão 1, p. 10.

${ }^{11}$ DERRIDA. Le concept de littérature comparée et les problèmes théorique de la traduction, sessão 1, p. 9.
} 
Comparada. É preciso notar que Derrida não judica, a favor ou contra, essa tentação estrutural, ou a ausência de um sentido rigorosamente definido do que é a Literatura, apenas expõe um modo de funcionamento, cujas aporias e ausências de definição se apresentam como demandas estruturais da constituição histórica dessa Instituição.

\section{A TENTAÇÃO ESTRUTURAL À ABERTURA ENCICLOPÉDICA: DOBRA CRÍTICA}

A ideia da “tentação estrutural à abertura enciclopédica” é extraída por Derrida da leitura de um artigo da Encyclopedia Universalis de René Étiemble sobre Literatura Comparada. ${ }^{12}$ Seria importante destacar que Étiemble é considerado uma das mais importantes cabeças pensantes dos aspectos programáticos da Literatura Comparada. Especialista em confucionismo e tradutor de poesia chinesa e hai-kai, René Étiemble orienta sua pesquisa pela busca de arquétipos e outros aspectos universais que poderiam estar presentes nas formas literárias de todos os tempos e lugares. Derrida comenta seu artigo pelo modo como ele procura estabelecer as vocações básicas da Literatura Comparada, ressaltando os meios e instrumentos, mas sem se referir à estrutura do projeto:

Este artigo de Enciclopédia é ele mesmo um artigo enciclopedista, isto quer dizer que ele descreve o conceito de Literatura Comparada, a vocação e destinação essencial dessa magnífica disciplina como uma destinação enciclopédica e enciclopedista. $\mathrm{O}$ autor se regozija do caráter enciclopédico, o que não parece colocar para ele nenhum problema, a não ser o problema do tempo necessário para que cada comparatista obtenha uma formação suficiente, os créditos que o departamento deverá obter se os políticos tomarem consciência da necessidade da literatura comparada, e todos os meios técnicos que ela deve por em obra. Todas as questões se portam nas modalidades do "colocar em obra" desta enciclopédia e não a essência ou estrutura do seu projeto. ${ }^{13}$

Apesar de tudo, o artigo de Étiemble parece a Derrida bem razoável do ponto de vista da tentativa de legitimação da disciplina. No entanto, o movimento que a legitimaria é o movimento mesmo com o qual se livra da racionalidade da disciplina

\footnotetext{
12 Disponível, através de dispositivo pago, em: <http://www.universalis.fr/encyclopedie/litterature-la-litterature-comparee/>.

${ }^{13}$ DERRIDA. Le concept de littérature comparée et les problèmes théorique de la traduction, sessão 1, p. 11
} 
que procura defender, conduzindo, ao ver de Derrida, "a tais extremismos, que isto nos dá a pensar sobre a estrutura finalmente paranóica desta racionalidade enciclopédica”. ${ }^{4}$

Se seguirmos a lógica imperturbável desse artigo e seu projeto declarado, ao menos através do recorte de Derrida, o mundo inteiro se tornaria um imenso departamento de Literatura Comparada administrado pela Associação Internacional de Literatura Comparada. Em certos momentos pode parecer ao leitor do seminário que Derrida está imprimindo um tom jocoso à sua leitura do artigo de Etiemble, mas mais adiante pode-se ler:

Se tomo o manifesto de Etiemble publicado na Encyclopedia universalis, não é para abusar dele ou torná-lo derrisório. Eu creio que ele exprime em traços largos e grandes, diretamente e sem volteios, o espírito que preside, que não pode senão presidir a fundação de princípios, a constituição mesma de todos departamentos de Complit (to be complete or not to be). ${ }^{15}$

Com isso Derrida delineia novamente a aporia na qual está colocada a Literatura Comparada como instituição universitária: o horizonte ou ideal de completude é o caráter mesmo de generalidade que traz as dificuldades de legitimação e definição dos objetos; por outro lado, ao se tentar restringir, delimitar e legitimar os seus objetos de estudo, perder-se-ia a generalidade e, portanto, o horizonte de completude. Derrida observa que tudo aquilo que esse projeto tem de mais razoável, no mais legítimo emprego das competências requeridas, dentro disso que o alarga por todas as línguas, todas as formas de arte, discursivas ou não, plásticas e musicais, e no limite, a toda cultura, vêm, necessariamente sobre o título de literatura geral, a dissolver a essência ou conceito de literatura que se supõe regular o modo de se dispor dos objetos e das competências. O que é a Literatura e o que não é nisso tudo? "Não há nada de fortuito no fato de que Étiemble não tenha colocado essa questão.”16

Mas eis que Derrida sugere a possibilidade da retomada de uma intenção à legitimidade do programa de Etiemble, sob outra perspectiva.

${ }^{14}$ DERRIDA. Le concept de littérature comparée et les problèmes théorique de la traduction, sessão 1, p. 11.

${ }^{15}$ DERRIDA. Le concept de littérature comparée et les problèmes théorique de la traduction, sessão 1, p. 14.

${ }^{16}$ DERRIDA. Le concept de littérature comparée et les problèmes théorique de la traduction, sessão 1, p. 15 
Eu me interesso menos em marcar o caráter, a um só tempo, utópico e totalitário, generalista e paranóico, do que reconhecer nele, em seu princípio mesmo, em sua pretensão simples à legitimidade uma forma de dobra crítica. (...) Onde está a dobra crítica? Onde situar esta dobra crítica - no projeto, mesmo independente de todas as dificuldades empíricas que ela pode e tem para se realizar? (...) É precisamente dentro deste valor de generalidade, dentro do conceito de literatura geral que organiza e desorganiza este discurso. ${ }^{17}$

A noção de “dobra crítica” é anunciada, mas permanecerá realmente como “dobra” durante o resto do seminário, sem um desdobramento pleno. Todavia, é possível vislumbrar algumas consequências que esta noção acarretará para a leitura de Derrida sobre a instituição Literatura Comparada. Em primeiro lugar poderíamos pensar que a noção de dobra crítica se relaciona com a pergunta sobre o que é a literatura. Esta pergunta não teria mais um estatuto meramente ontológico, que devesse ser respondida através da busca de uma essência da Literatura ou da Literariedade, mas tratar-se-ia de uma pergunta crítica que recolocaria permanentemente em crise a possibilidade de uma definição de literatura. É importante notar aqui os germes de elaborações posteriores no pensamento de Derrida sobre a Literatura, como por exemplo, a tese de que a Literatura é uma "instituição que tende a transbordar a institucionalidade"18 ou que transgride a sua própria institucionalidade. Ou ainda, dito de modo - mais parcimonioso e paradoxal - a Literatura como “instituição sem intituição" (institutionless institution). ${ }^{19}$ Daí o valor estruturalmente necessário, apontado por Derrida, de generalidade que organiza e desorganiza o campo da Literatura Comparada, pois faz parte desse campo supor e ao mesmo tempo questionar a identidade tácita entre os chamados fenômenos literários.

Em segundo lugar, a noção de “dobra crítica” deslocaria a ideia de uma suposta “crise” da Literatura Comparada, no sentido de uma degenerescência. Rigorosamente falando, seria legítimo falar da crise dessa disciplina se ela tivesse um telos bem definido a partir do qual fosse possível assinalar um desvio. Mas como se vê durante o seminário, o argumento de Derrida segue na direção justamente de afirmar que esse telos permanece como pergunta crítica que organiza e desorganiza a instituição disciplinar. Aí também se articulam as relações entre a Literatura Comparada e os problemas de tradução. A Literatura Comparada seria um lugar de tradução num sentido

\footnotetext{
${ }^{17}$ DERRIDA. Le concept de littérature comparée et les problèmes théorique de la traduction, sessão 1, p. 15. (grifo do autor)

${ }^{18}$ DERRIDA. Acts of literature, p. 36. (tradução nossa)

${ }^{19}$ DERRIDA. Acts of literature, p. 42.
} 
amplo, da tradução entre as línguas e literaturas nacionais, é certo; mas também da tradução de diferentes práticas teóricas e discursivas. Temos que lembrar também que toda tentativa de definir a literatura ou supor identidade entre os fenômenos literários, não apenas definem a literatura, mas sempre a literatura e seu “Outro”. Com isso, temos no campo da Literatura Comparada, somando-se aos tipos anteriormente citados de tradução, o problema da tradução da literatura em seu outro e vice-versa. Pois que a Literatura Comparada, como instituição universitária, parte dos fenômenos literários para empreender atividades não literárias, de pesquisa, acadêmicas; e ao mesmo tempo estabelece, a partir dessas atividades, mesmo que provisoriamente e tacitamente, balizas de inteligibilidade para aquilo que chamamos "fenômeno literário".

A noção de dobra crítica ressalta, então, uma legitimidade paradoxal. A dobra crítica figura como um lugar de onde se enunciam perguntas quanto às definições mútuas da Literatura e seu "Outro”, quanto ao seu caráter disciplinar e institucional; lugar onde as perguntas quanto às possibilidades das identidades (identidade de uma língua nacional, identidade dos fenômenos literários consigo mesmos, identidade de uma instituição, identidade entre original e tradução) seriam incessantemente retomadas.

No interior dessa esfera problemática e histórica aparecem também as temíveis questões da história da literatura; não somente de suas obras, mas de seu conceito e seu nome. Derrida indaga “em que momento, em que condições começa-se a falar de literatura, e não mais confundi-la com a poesia e as 'belas letras'?”, ${ }^{20}$ destacando aí os dramas de (auto)nomeação e o ato fundacional a partir do qual fala-se de literatura. Essa pergunta se relaciona com temas trabalhados no seminário anterior de Derrida em 197879 sob o título de "Do Direito à Literatura”, no qual ele persegue uma possível formação do conceito estrito de literatura no século 18.

Ao terminar a primeira sessão, Derrida acena com algumas perguntas:

Será que uma definição de literatura no sentido estrito, se existe um, é compatível com o projeto enciclopédico de uma literatura geral e comparada? Não se pode reconhecer a literatura ou os fenômenos literários, a menos que se saiba, se tenha uma pré-compreensão do que quer dizer "literatura" ou "literaridade" da literatura. Seria essa é uma questão crítica? Em que sentido? Abriria ela uma crise? Colocaria ela

${ }^{20}$ DERRIDA. Le concept de littérature comparée et les problèmes théorique de la traduction, sessão 1, p. 15. 
em crise o conceito de instituição de "literatura comparada”? Que relação ela tem com o problema da tradução ${ }^{21}$

Essas perguntas fornecem as coordenadas a partir das quais Derrida procurará esboçar, na próxima sessão do seminário, a hipótese de que a literatura seja um “conjunto de nomes próprios”. Tal hipótese, tomada apenas em seu valor heurístico, viabiliza a exploração da relação da Literatura Comparada com os problemas teóricos da tradução. Mas isso já é assunto para outro artigo.

\begin{abstract}
In the seminar "Le concept de littérature comparée et les problèmes théorique de la traduction”, lectured in Yale, 1979-80, Jacques Derrida explores institucional and disciplinary aspects of "Comparative Literature”. This paper retraces and discusses the arguments of the first session of 1979's seminar to point out its connections to future formulations, such as the notion of literature as an "institutionless institution”.
\end{abstract}

\title{
KEYWORDS
}

Comparative Literature, Jacques Derrida, Institution

\section{REFERÊNCIAS}

DERRIDA, Jacques. This strange institution called literature: an interview with Jacques Derrida. Trans. Derek Attridge. In: _. Acts of literature. Ed. Derek Atridge. London/New York: Routledge, 1991. p. 33-75.

DERRIDA, Jacques. Le concept de littérature comparée et les problèmes théorique de la traduction. In: DERRIDA ARCHIVE AT LANGSON LIBRARY, University of California at Irvine, 2010.

ÉTIEMBLE, René. La littérature comparée. Disponível em: $<$ http://www.universalis.fr/encyclopedie/litterature-la-litterature-comparee/>. Acesso em: 15 jul. 2010.

${ }^{21}$ DERRIDA. Le concept de littérature comparée et les problèmes théorique de la traduction, sessão 1, p. 16. 